\section{Ammonia Excretion and the Clearance of Mepacrine}

IT has been found that the urinary excretion of mepacrine has a relation to the excretion of ammonia. The simplest description of this empirical relation is that the mepacrine clearance from the plasma is directly proportional to the rate of excretion of ammonia. This may be expressed thus :

$$
\frac{U M \times V}{P M}=k U \mathrm{NH}_{3} \times V,
$$

where $U M$ is urinary mepacrine in micrograms/litre $\nabla$ is volume of urine in $\mathrm{ml} . / \mathrm{min} . ; P M$ is plasma mepacrine in micrograms/litre; $\mathrm{UNH}_{3}$ is urinary ammonia in mgm. $\mathrm{NH}_{3}-\mathrm{N} / 100 \mathrm{ml}$; and $k$ a constant equal to $2 \cdot 4$.

Equation (1) may be written in the form :

$$
P M=\frac{1}{k} \frac{U M}{U \mathrm{NH}_{3}}
$$

In this form the relation can be used to estimate plasma mepacrine concentration from the urinary concentration of mepacrine and ammonia only, without regard to their rates of excretion. The relation has been studied and found to hold between the following limits : $U M$ from 260 to 4,900 micrograms/ litre; $V$ from 1 to $10 \mathrm{ml}$. $/ \mathrm{min}$.; $P M$ from $12 \cdot 2$ to 40.2 micrograms/litre; $U \mathrm{NH}_{3}$ from 3.4 to $59.5 \mathrm{mgm}$. $\mathrm{NH}_{3}-\mathrm{N} / 100 \mathrm{ml}$.

The accompanying table shows the plasma mepacrine concentrations ( $P M$ calc.), calculated from equation (2) for two separate urine samples obtained from each of ten subjects, compared with the plasma mepacrine concentrations directly determined by Masen's method ${ }^{1}$ on blood samples drawn in the middle of each urine-collecting period ( $P M$ obs.).

OBSERVED PLASMA MEPACRINE CONCENTRATION (PM OBS.) COMPARED WITH THE CALCULATED VALUE (PM CALC.).

\begin{tabular}{|c|c|c|c|}
\hline Volunteer No. & Period & $\begin{array}{r}P M \text { (obs.) } \\
\text { microgram/litre }\end{array}$ & $\begin{array}{c}P M \text { (calc.) } \\
\text { microgram/litre }\end{array}$ \\
\hline 1 & II & $40 \cdot 2$ & $38 \cdot 2$ \\
2 & II & $32 \cdot 8$ & $41 \cdot 8$ \\
3 & II & $32 \cdot 3$ & $33 \cdot 8$ \\
4 & II & $29 \cdot 3$ & $33 \cdot 4$ \\
5 & II & $28 \cdot 5$ & $25 \cdot 8$ \\
& I & $26 \cdot 6$ & $22 \cdot 7$ \\
6 & II & $25 \cdot 4$ & $26 \cdot 2$ \\
7 & II & $23 \cdot 8$ & $24 \cdot 6$ \\
8 & II & $23 \cdot 0$ & $16 \cdot 2$ \\
9 & II & $19 \cdot 9$ & $24 \cdot 6$ \\
& II & $18 \cdot 4$ & $30 \cdot 6$ \\
10 & II & $17 \cdot 4$ & $14 \cdot 5$ \\
& II & $16 \cdot 3$ & $19 \cdot 4$ \\
& II & $15 \cdot 8$ & $14 \cdot 6$ \\
& II & $13 \cdot 9$ & $17 \cdot 4$ \\
& II & $13 \cdot 0$ & $13 \cdot 7$ \\
& II & $12 \cdot 2$ & $14 \cdot 6$ \\
& & & $14 \cdot 0$ \\
\hline
\end{tabular}

The standard deviation of the differences between $P M$ (obs.) and $P M$ (calc.) was found to be $\pm 4 \cdot 0$ micrograms per litre, with a mean plasma concentration of $22 \cdot 2$ micrograms per litre, whereas the standard deviation of $P M$ (obs.) (mean of triplicates) was itself \pm 3.5 micrograms per litre.

The striking relation expressed in equation (1) has, so far as we know, not previously been reported. There is no reason to suppose that this relation is confined to the excretion of mepacrine. It possibly depends on the fact that mepacrine may behave like a substituted ammonia compound, in which case the relation may be applicable to the excretion of other such compounds.
For example, the observations by Haag et al. ${ }^{2}$ that quinine is excreted more rapidly in acid urine than in alkaline suggests that this drug behaves like mepacrine. This possibility is being investigated.
B. G. Maegraith.
G. M. Brown.
D. S. Parsons.
C. N. Partington.
R. J. ROSSITER
J. L. Rennie.

K. N. IRVINE.

R. E. Havard.

J. C. LeEs.

Army Malaria Research Unit, Oxford. Nov. 7.

'Masen, J. M., J. Biol. Chem., 148, 529 (1943).

${ }^{2}$ Hag, H. B., Larson, P. S., and Schwartz, J. J., J. Pharm. Exp. Ther, 79, 136 (1943)

\section{Viscero-Motor Reflexes}

Strmulatron of the sensory nerves of the abdominal viscera has given mixed results in the hands of different observers. Miller and his colleagues, ${ }^{1,2}$ obtained movements of the hind legs and belly muscles on centripetal stimulation of the mesenteric nerves of decapitated cats. Squeezing the intestine and traction on the mesentery were also effective. Lewis and Kellgren ${ }^{3}$, on the other hand, obtained no movement of the legs or belly muscles on pinching the duodenum, but did record a rise of blood pressure. Pinching the pancreas caused both muscle movements and rise of blood pressure. McDowall, in 1942 , stated that occlusion of the carotid and vertebral arteries of a decerebrated cat produces a 'spinal' preparation devoid of shock, and that certain stimuli, such as stretching the gut, cause marked limb movements. He pointed out that a successful result is obtained only if the preparation is not overventilated.

We also find that the presence or absence of spinal reflex movements following stimulation of the intestine depends on the preparation of the animal. When the brain of the cat is destroyed above the second cervical vertebra, no, or only very small, movements of the hind limbs follow a strong pinch of the duodenum, but a pinch of a small part of the head of the pancreas causes strong movements; a rise of blood pressure follows each pinch. This confirms the findings of Lewis and Kellgren. On the other hand, when the spinal cord is transected in the upper thoracic region and the cat then decerebrated, a gentle squeeze of any part of the small and large intestine causes strong movements of the hind legs. Other effective stimuli include scraping or scratching the serous coat or heating the gut, and also pulling or rubbing the mesentery. We find that the small intestine is less sensitive along its free border than near the attachment of the mesentery. Responses follow mechanical or thermal stimulation of an adequate area of the gut or repeated stimulation of a smaller area. All stimuli have been applied to the outside of the intestine, and it is not yet possible to define the site of origin of the afferent impulses.

When the response to visceral stimulation is tested some three hours after the operation under ether anæsthesia, superficial and deep reflexes of the hind legs are very lively and easily elicited in both preparations. It is curious that there is so little correspondence between the general reflex activity of the hind limbs and the responses to visceral stimulation. The viscero-motor responses may deteriorate to extinction without apparent change in the general reflex activity of the limbs. It must be recalled that 